\title{
Apelin stimulates glucose uptake but not lipolysis in human adipose tissue ex vivo
}

\author{
C Attané ${ }^{1,2}$, D Daviaud ${ }^{1,2}$, C Dray $^{1,2}$, R Dusaulcy ${ }^{1,2}$, M Masseboeuf $^{1,2}$, D Prévot $^{1,2}$, \\ C Carpéné ${ }^{1,2}$, I Castan-Laurell ${ }^{1,2}$ and $P$ Valet $^{1,2}$ \\ ${ }^{1}$ INSERM, U858, F-31432 Toulouse, France \\ ${ }^{2}$ Institut de Médecine Moléculaire de Rangueil (I2MR), Université de Toulouse, UPS, IFR150, 1 Avenue Jean Pouhlès, BP 84225, F-31432 Toulouse Cedex 4, France \\ (Correspondence should be addressed to I Castan-Laurell at Institut de Médecine Moléculaire de Rangueil (I2MR), Université de Toulouse, UPS, IFR150; \\ Email: isabelle.castan@ inserm.fr)
}

\begin{abstract}
Apelin is a peptide present in different cell types and secreted by adipocytes in humans and rodents. Apelin exerts its effects through a G-protein-coupled receptor called APJ. During the past years, a role of apelin/APJ in energy metabolism has emerged. Apelin was shown to stimulate glucose uptake in skeletal muscle through an AMP-activated protein kinase (AMPK)-dependent pathway in mice. So far, no metabolic effects of apelin have been reported on human adipose tissue (AT). Thus, the effect of apelin on AMPK in AT was measured as well as AMPK-mediated effects such as inhibition of lipolysis and stimulation of glucose uptake. AMPK and acetyl-CoA carboxylase phosphorylation were measured by western blot to reflect the AMPK activity. Lipolysis and glucose uptake were measured, ex vivo, in response to apelin on isolated adipocytes and explants from AT of the subcutaneous region of healthy subjects (body mass index: $25 \cdot 6$ $\pm 0.8 \mathrm{~kg} / \mathrm{m}^{2}, n=30$ in total). APJ mRNA and protein are present in human AT and isolated adipocytes. Apelin stimulated AMPK phosphorylation at Thr-172 in a dose-dependent manner in human AT, which was associated with increased glucose uptake since $\mathrm{C}$ compound $(20 \mu \mathrm{M})$, an AMPK inhibitor, completely prevented apelin-induced glucose uptake. However, in isolated adipocytes or AT explants, apelin had no significant effect on basal and isoprenaline-stimulated lipolysis. Thus, these results reveal, for the first time, that apelin is able to act on human AT in order to stimulate AMPK and glucose uptake.
\end{abstract}

Journal of Molecular Endocrinology (2011) 46, 21-28

\section{Introduction}

Apelin is a peptide, identified as the endogenous ligand of APJ, a ubiquitously expressed G-protein-coupled receptor (Tatemoto et al. 1998). Apelin is synthetized as a 77-amino-acid prepropeptide, which is cleaved in different fragments including apelin-36, apelin-17, apelin-13, and the posttranslationally [Pyr1]apelin-13 with a conversion of the N-terminal glutamate to pyroglutamate preventing enzymatic breakdown and thus preserving biological activity (Tatemoto et al. 1998). Prior to being revealed as an adipocyte-secreted factor (adipokine), apelin was known not only to exert several central and peripheral effects on different tissues such as the regulation of the cardiovascular, immune, and gastrointestinal functions but also on fluid homeostasis, angiogenesis, proliferation of different cell types, and embryonic development (Kleinz \& Davenport 2005). Recently, we have demonstrated that i.v. injection of apelin, at physiological dose, was able to decrease glycemia in mice (Dray et al. 2008). Moreover, during a hyperinsulinemic-euglycemic clamp, an increased glucose uptake was observed in adipose tissue (AT) and skeletal muscle (Dray et al. 2008). Apelin-stimulated glucose transport in soleus muscle was dependent on AMP-activated protein kinase (AMPK) activation (Dray et al. 2008). A similar stimulation of AMPK by apelin has also been described in cultured C2C12 myotubes (Yue et al. 2009). Taken together, these independent observations support a physiological role of apelin in glucose metabolism. Recent data have also highlighted an important role for apelin in lipid metabolism. Higuchi et al. (2007) showed that prolonged treatment of apelin (daily i.p. injection of apelin for 2 weeks) decreased the triglycerides content of AT and the weight of different fat depots in chow-fed and obese mice. In addition, changes in uncoupling protein-1 (UCP-1) expression in brown AT as well as changes in UCP-3 expression in skeletal muscle were observed after apelin treatment but no metabolic effects were studied (Higuchi et al. 2007).

In humans, different studies have reported changes in plasma apelin concentration and variations of apelin expression in different tissues between physiological and pathological situations (Carpéné et al. 2007). Insulin has been shown to be one of the main regulating factors of apelin expression and secretion (Boucher et al. 2005). Circulating apelin levels as well as AT expression increase in obese and hyperinsulinemic subjects (Boucher et al. 
2005, Castan-Laurell et al. 2008). Plasma apelin levels are also raised in morbidly obese (Heinonen et al. 2005) and type 2 diabetic (Soriguer et al. 2009) subjects. Nonobese patients with impaired glucose tolerance or with type 2 diabetes also exhibited higher concentrations of apelin when compared with control subjects (Li et al. 2006). The high apelin concentrations can be modulated by weight loss. Indeed, it was shown that diet-induced weight loss reduces plasma apelin levels in women with moderate obesity (Castan-Laurell et al. 2008), but not significantly in patients with metabolic syndrome (Heinonen et al. 2009). Bariatric surgery leads to a significant decrease in plasma apelin in morbidly obese subjects with impaired fasting glucose or type 2 diabetes before surgery (Soriguer et al. 2009). Moreover, the combination of two antidiabetics such as metformin and rosiglitazone in patients with type 2 diabetes improves glycemic profile and allows an increase in plasma apelin concentrations (Kadoglou et al. 2010). Altogether these studies suggest that the increased levels of apelin might be, in early stage of metabolic disease, a compensatory mechanism delaying the onset of insulin resistance.

So far, to our knowledge, metabolic effects of apelin on human AT and the effect of apelin on AMPK activity in AT have not been published. Adipocytes are involved in lipid storage (lipogenesis) through lipid and glucose uptake but also in triglyceride breakdown (lipolysis) into fatty acids and glycerol (Lafontan 2008). Thus, we measured lipolysis and glucose uptake in AT (subcutaneous abdominal fat depot) from healthy subjects in response to increasing concentrations of apelin-13. The following results show that apelin stimulates AMPK and glucose uptake but had no effect on lipolysis in the conditions used.

\section{Materials and methods}

\section{Subjects}

The study was performed according to the Declaration of Helsinki, and human AT was collected according to the guidelines and approval of the Ethical Committee of Rangueil Hospital in Toulouse from healthy women undergoing abdominal dermolipectomy for plastic surgery (body mass index: $25 \cdot 6 \pm 0 \cdot 8 \mathrm{~kg} / \mathrm{m}^{2}$, age: $43 \cdot 2 \pm 2 \cdot 7$ years, $n=30$ in total, each tissue was either attributed to one or several protocols). All of them were drug free and healthy. No clinical data from these patients were available.

\section{Human AT preparation}

Human subcutaneous AT was either digested by collagenase (type II, Sigma-Aldrich Co.) in order to get isolated adipocytes or minced into very small pieces (1-2 mg) to get explants. The explants were washed two times in PBS at $37^{\circ} \mathrm{C}$, centrifuged for $10 \mathrm{~min}$ at $850 \mathrm{~g}$ at room temperature in order to remove the connective tissue, and the medium was discarded. Isolated adipocytes were obtained after mincing AT in $5 \mathrm{ml}$ of DMEM (Gibco, Invitrogen) supplemented with $1 \mathrm{mg} / \mathrm{ml}$ collagenase and $1 \%$ albumin (BSA) for $30 \mathrm{~min}$ at $37^{\circ} \mathrm{C}$ under shaking. Digestion was followed by filtration through a $150 \mu \mathrm{m}$ screen and the floating adipocytes were separated from the medium containing the stroma vascular fraction and washed twice in DMEM.

\section{APJ mRNA expression in human AT}

Total RNAs $(1 \mu \mathrm{g})$ were isolated from either AT using RNeasy Lipid Tissue kits (Qiagen, Courtaboeuf, France) or isolated adipocytes using RNeasy kit (Qiagen). They were then reverse transcribed using random hexamers and Superscript II reverse transcriptase (Invitrogen). Real-time PCR was performed as previously described (Boucher et al. 2005). Briefly, real-time PCR was performed on $12.5 \mathrm{ng}$ cDNA with both sense (hAPJ sense: GCCCTTGCTTTCTGAAAATCA) and antisense (hAPJ reverse: GGACAGTTAAAGGATGTGCATAGGA) oligonucleotides (Eurogentec, Angers, France) in a final volume of $20 \mu \mathrm{l}$ using SYBR Green qPCR Master Mix (Eurogentec, Seraing, Belgium). Fluorescence was monitored and analyzed in a GeneAmp 7500 detection system instrument (Applied Biosystems, Warrington, UK). In parallel, analysis of the $18 \mathrm{~S}$ ribosomal RNA was performed using the ribosomal RNA control Taqman Assay kit (Applied Biosystems) to normalize gene expression.

\section{Immunohistochemical study of APJ}

AT was fixed overnight in a paraformaldehyde $4 \%$ solution, then hydrated, and paraffin-embedded. AT sections were blocked with $1 \%$ BSA in Tris buffer for $1 \mathrm{~h}$ at room temperature. Sections were then incubated with APJ monoclonal (anti-human) antibody (R\&D Systems, Lille, France) overnight at $4{ }^{\circ} \mathrm{C}$ (1:25 dilution). Control sections were stained with $\operatorname{IgG}$ mouse serum used at the same dilution as APJ antibody. As a secondary antibody, alkaline phosphatase (DakoCytomation, Trappes, France) was used at 1:100 dilution. Antigen visualization was achieved with an alkaline phosphate system (BCIP/NBT Substrate System) added with Levamisole (DakoCytomation) in order to suppress nonspecific staining.

\section{Glucose uptake}

AT explants were preincubated for $10 \mathrm{~min}$ in KrebsHenseleit (KH) buffer, $\mathrm{pH} 7 \cdot 4$, containing BSA $(2 \mathrm{mg} / \mathrm{ml})$ and $20 \mathrm{mM}$ Hepes. Explants were then incubated for $45 \mathrm{~min}$ in the presence or absence of different concentrations of [Pyr1] apelin-13 (BACHEM distribution services) or $100 \mathrm{nM}$ insulin (Sigma-Aldrich 
Co.). [Pyr1]apelin-13 has been chosen as a stable biological active apelin isoform (Kleinz \& Davenport 2005). In order to test the involvement of AMPK, C compound was added 20 min before apelin. For glucose transport, explants were transferred to another vial containing $\mathrm{KH}$ medium supplemented with $0 \cdot 1 \mathrm{mM}$ 2-deoxyglucose (2-DG) and D- $\left[{ }^{3} \mathrm{H}\right]$-2-DG $(0 \cdot 25 \mu \mathrm{Ci} / \mathrm{ml})$ for $10 \mathrm{~min}$. All the incubations were carried out at $37^{\circ} \mathrm{C}$ under a $95 \% \mathrm{O}_{2} / 5 \% \mathrm{CO}_{2}$ atmosphere. Explants were then washed two times in PBS under shaking and then lysed by using Precellys 24 automated biological sample lyser with CK-14 beads vials (Ozyme, Saint Quentin, France) in $500 \mu \mathrm{l} \mathrm{NaOH}(1 \mathrm{M})$. The infranatant was recovered for further extraction and $500 \mu \mathrm{l} \mathrm{HCl}(1 \mathrm{M})$ were added to each sample in order to restore $\mathrm{pH}$ neutrality. The total amount of D- $\left[{ }^{3} \mathrm{H}\right]-2-\mathrm{DG}$ was quantified after addition of a perchloric acid (6\%) solution. In an other vial, D- $\left[{ }^{3} \mathrm{H}\right]-2-D G$ 6-phosphate was precipitated by the use of zinc sulfate $(0 \cdot 3 \mathrm{M})$ and barium hydroxide $(0 \cdot 3 \mathrm{M})$. The amount of 2-DG internalized was calculated by the difference between the radioactivity found in total 2-DG and nonphosphorylated 2-DG found in the supernatants.

Glucose uptake by isolated adipocytes was measured as previously described (Iglesias-Osma et al. 2005). Briefly, adipocytes (1:10 dilution) were incubated with $1 \mu \mathrm{M}$ of apelin or $100 \mathrm{nM}$ insulin as a positive control for $45 \mathrm{~min}$ at $37^{\circ} \mathrm{C}$ and $0.4 \mu \mathrm{Ci}$ 2-DG were added at a final concentration of $0 \cdot 1 \mathrm{mM}$ for $10 \mathrm{~min}$. Assays were stopped with $100 \mu \mathrm{M}$ cytochalasin $\mathrm{B}$ and aliquots of cell suspension were centrifuged in microtubes containing di-isononyl phthalate, which allowed separation of adipocytes from the buffer and counting of the radioactive intracellular 2-DG.

\section{Lipolysis}

Lipolysis was realized in Krebs-Ringer-Hepes (KRH) buffer with $2 \%$ BSA. In all, $100 \mu \mathrm{l}$ AT microexplants or adipocytes (1:10 dilution) were incubated in $1 \mathrm{ml} \mathrm{KRH}$ for $1 \mathrm{~h}$ at $37^{\circ} \mathrm{C}$ under gentle shaking in the presence of different concentrations of apelin or in $1 \mu \mathrm{M}$ isoprenaline (a $\beta$-adrenergic agonist) as a positive control. The reaction was stopped once the tubes were on ice. Glycerol released in the medium was measured in a $30 \mu \mathrm{l}$ aliquot using the Glycerol-Free Reagent kit (Sigma) while nonesterified fatty acids (NEFA) were measured in $15 \mu \mathrm{l}$ of the medium by the WAKO NEFA kit (WAKO Chemicals, Montbonnot St Martin, France).

\section{Western blots}

AT explants were lysed as described above (Precellys) and loaded ( $50 \mu \mathrm{g}$ protein per lane) on $10 \%$ SDS-PAGE gel and transferred to nitrocellulose membrane (Schleicher-Schuell). Membranes were blotted with
anti-phospho-AMPK $\alpha$-Thr-172 or anti-phospho-acetyl-CoA carboxylase (ACC)-Ser79 antibodies (Cell Signaling Technology, Beverly, MA, USA) used at 1:1000 dilution in Tris-buffered saline containing 5\% BSA and Tween-20 at $0.01 \%$. As a secondary antibody, anti-rabbit-HRP was used (1:3000 dilution). Membranes were probed with $\beta$-actin for total proteins. Immunoreactive proteins were detected using the ECL Plus (GE Healthcare, Orsay, France) and quantified by Image Quant TL software (GE Healthcare Bio-Sciences, Uppsala, Sweden).

\section{Statistical analysis}

Data are presented as means \pm s.E.M. Analysis of differences between the groups was performed with one-way ANOVA followed by post hoc Bonferroni's or Dunnett's test, when appropriate and $P<0.05$ was considered to be significant.

\section{Results}

\section{Expression of APJ receptors in human AT}

We have previously shown that APJmRNAs were present in human AT (Castan-Laurell et al. 2008, Dray et al. 2010). In this study, we further delineated the presence of both APJmRNA and protein in isolated adipocytes compared to the entire AT. As shown in Fig. 1, APJ mRNA levels were lower in isolated adipocytes than in AT. APJ proteins were also visualized in human AT since a positive immunostaining was observed in the periphery of adipocytes compared to control.

\section{Effect of apelin on AMPK}

AMPK has been revealed as a target of apelin signaling in muscle (Dray et al. 2008, Yue et al. 2009), thus the effect of apelin on AMPK activation was studied in human AT. Time-course studies in AT explants revealed that $10 \mathrm{nM}$ apelin induced the phosphorylation of AMPK that was maximal at $10 \mathrm{~min}$ (Fig. 2A). In total, $2 \mathrm{mM}$ 5 -aminoimidazole-4-carboxamide-1- $\beta$-D-ribofuranoside (AICAR) incubated for $60 \mathrm{~min}$ was used as a positive control. Moreover, apelin stimulated, in parallel, the phosphorylation of AMPK and ACC, its downstream target enzyme, in a dose-dependent manner with a significant effect at $10 \mathrm{nM}$ (Fig. 2B). Thus, apelin activates AMPK in human AT. Metabolic effects mediated by apelin involving AMPK were then studied.

\section{Effect of apelin on lipolysis}

Both glycerol and NEFA releases were measured as final products of triglyceride hydrolysis after $1 \mathrm{~h}$ incubation with different agents. Isoprenaline (a $\beta$-adrenergic 


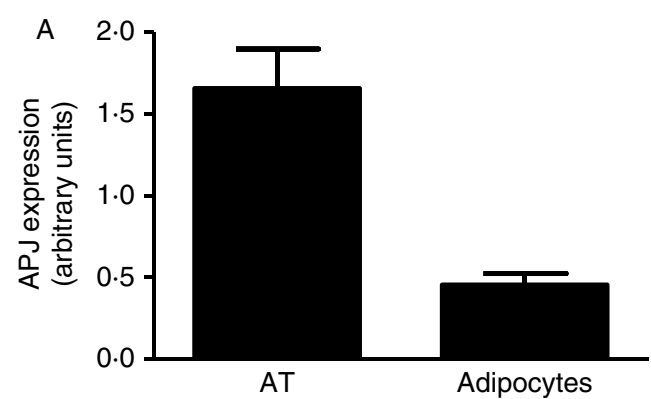

B Control APJ

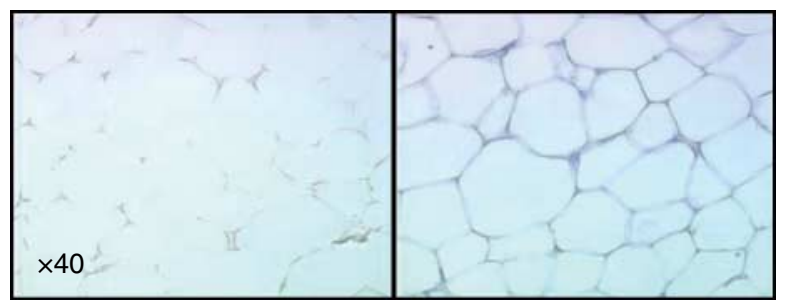

Figure 1 Expression of APJ, the apelin receptor, in human AT. (A) mRNA levels of APJ in entire adipose tissue (AT) and isolated adipocytes. Results are mean \pm S.E.M. of eight independent experiments. (B) Representative immunostaining without (control) or with anti-APJ antibody (APJ) in human AT.

agonist) was used at $1 \mu \mathrm{M}$ as a control of maximal lipolytic activation and AICAR was used at $2 \mathrm{mM}$ as an activator of AMPK (Gaidhu et al. 2009). Isoprenaline stimulated the basal release of glycerol and NEFA from AT explants whereas AICAR decreased basal lipolysis (Fig. 3A). However, apelin, whatever the concentrations used, had no significant effect on basal and isoprenaline-stimulated lipolysis (Fig. 3A). In addition, in isolated adipocytes, apelin at $10 \mathrm{nM}$ and $1 \mu \mathrm{M}$ did not have significant effect on lipolysis. When added at the same time along with isoprenaline, apelin did not modify the response of the $\beta$-adrenergic agonist, while $100 \mathrm{nM}$ insulin was antilipolytic (Fig. 3B).

\section{Effect of apelin on glucose uptake}

Insulin, as a positive control, stimulated glucose uptake in human AT explants (Fig. 4A). Apelin stimulated glucose uptake in a dose-dependent manner, with a significant effect at $10 \mathrm{nM}$, but to a lower extend compared to insulin (1.56-fold with $10 \mathrm{nM}$ apelin versus 2.0-fold with $100 \mathrm{nM}$ insulin). On isolated adipocytes, apelin had a weak effect (basal: $0 \cdot 16 \pm 0 \cdot 04 \mathrm{pmol} / \mathrm{g}$ protein; apelin $1 \mu \mathrm{M}$ : $0.23 \pm 0.06 \mathrm{pmol} / \mathrm{g}$ protein, $n=7-10$ ). The involvement of AMPK in apelin-stimulated glucose transport was underlined by the use of $\mathrm{C}$ compound, a selective AMPK inhibitor. C compound $(20 \mu \mathrm{M})$ prevented apelin-induced glucose uptake in human AT explants (Fig. 4B).

\section{Discussion}

In this study, we provide evidence that acute apelin treatment of human AT from healthy subjects stimulates AMPK phosphorylation and glucose uptake but has no effect on lipolysis. Thus, this study reveals, for the first time, an activation of AMPK by apelin in AT and
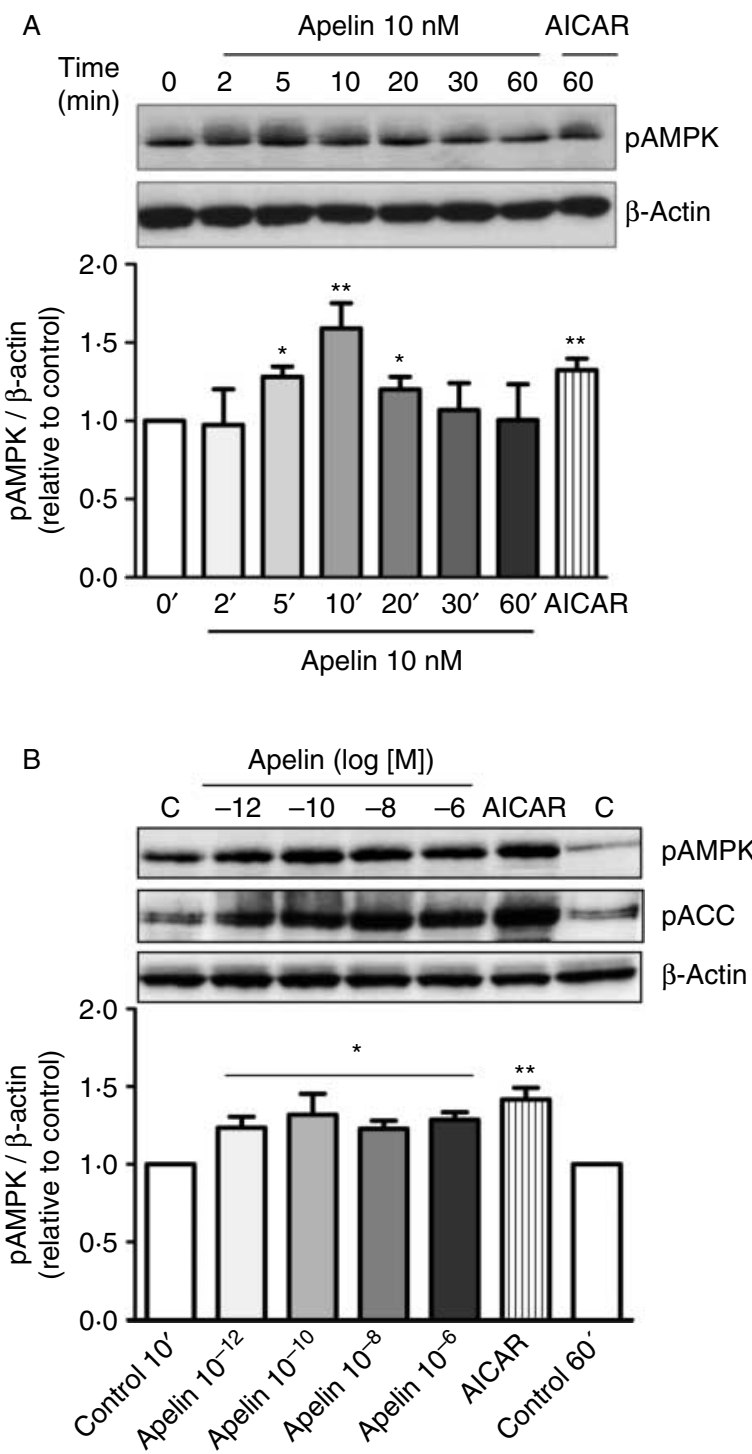

Figure 2 Apelin stimulates AMPK phosphorylation. (A) Representative blot of in vitro time-course study of Thr-172 AMPK phosphorylation in the presence of apelin $(10 \mathrm{nM})$ or AICAR $(2 \mathrm{mM})$, used as a positive control and incubated for $60 \mathrm{~min}$. $\beta$-Actin was used to evaluate total proteins, $n=4$. The graph shows the quantified data, ${ }^{\star} P<0.05,{ }^{* \star} P<0.01$ versus control. (B) Dose-response of apelin, at the indicated concentrations (incubation time: $10 \mathrm{~min}$ for apelin, $60 \mathrm{~min}$ for AICAR), on AMPK and ACC phosphorylation compared to control (C). $\beta$-Actin was used to evaluate total proteins. The graph shows the quantified data, $n=4,{ }^{*} P<0.05,{ }^{\star}{ }^{\star} P<0.01$ versus control. 

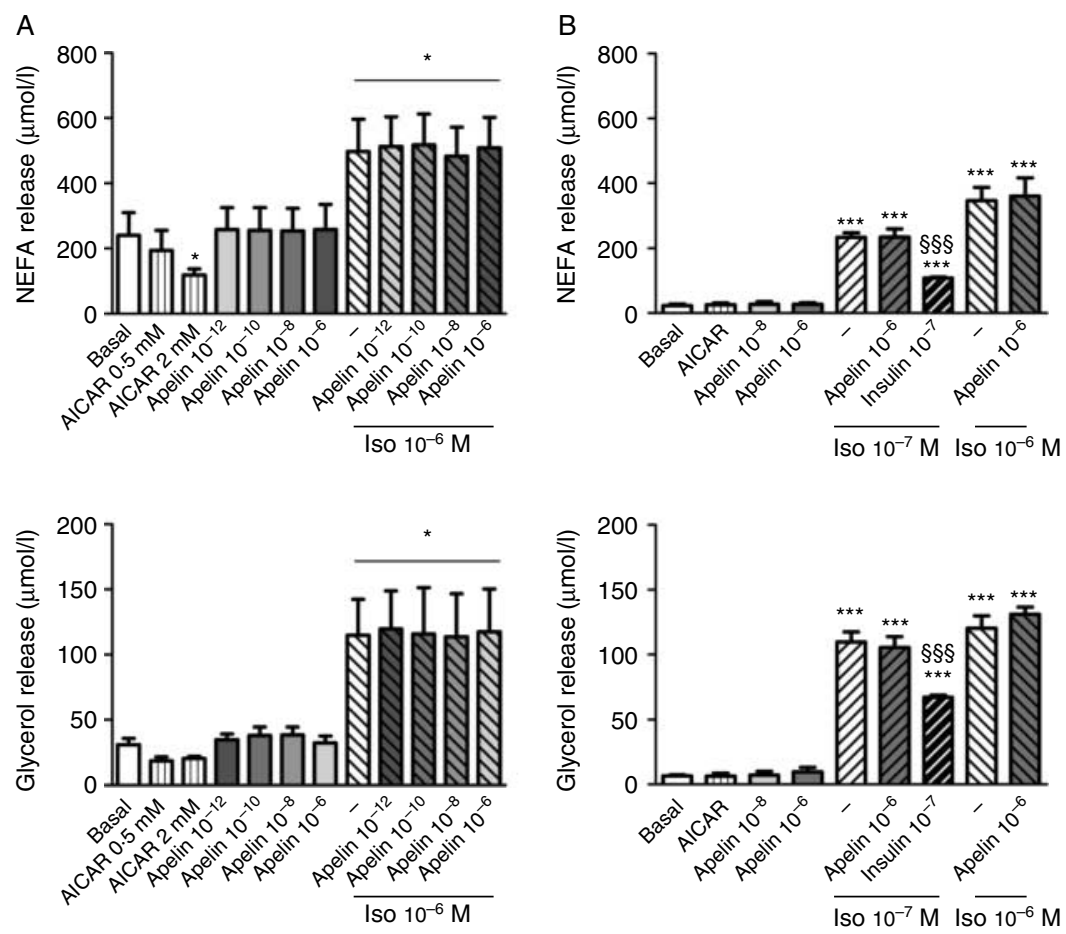

Figure 3 Effect of apelin on lipolysis in human AT explants (A) and isolated adipocytes (B). NEFA (top) and glycerol (bottom) releases upon basal lipolysis (white columns), under stimulation with AICAR alone, apelin alone or in the presence of isoprenaline (Iso, shaded columns) and insulin $100 \mathrm{nM}$ in the presence of isoprenaline. Results are the mean \pm S.E.M. of six independent experiments for AT explants and four independent experiments for isolated adipocytes. ${ }^{\star} P<0.05$ and ${ }^{* *} P<0.001$ versus basal; ${ }^{\S \S} P<0.001$ for insulin + isoprenaline versus isoprenaline alone.

functional metabolic effects of apelin on humans. These results are in line with our previous study performed in mice indicating that i) ex vivo, in soleus skeletal muscle, apelin stimulated AMPK and glucose uptake (Dray et al. 2008) and that ii) in vivo, apelin perfusion during a euglycemic-hyperinsulinemic clamp stimulated glucose uptake in AT.

Lipolysis is one of the main metabolic functions of AT. An upstream step controlling this process is the intracellular levels of cAMP. Apelin has been shown to reduce forskolin-stimulated cAMP production in different cell lines overexpressing APJ receptors through a pertussis-toxin-sensitive G-protein (Masri et al. 2002, Bai et al. 2008). Thus, an antilipolytic effect of apelin was expected but no modification of basal or isoprenaline-stimulated lipolysis was observed in the conditions used. Moreover, apelin has been shown to activate AMPK in skeletal muscle (Dray et al. 2008) while AMPK also regulates energy metabolism in AT (Daval et al. 2006). However, depending on the studies, it has been shown that, in rodents, activation of AMPK could lead either to inhibition or stimulation of lipolysis (Yin et al. 2003, Hutchinson et al. 2005, Daval et al. 2006, Omar et al. 2009). Very recently, it was shown that protein kinase A, once activated by lipolytic agents, inactivates AMPK to promote efficient lipolysis (Djouder et al. 2010). AMPK activation is thus viewed as a consequence of ongoing re-esterification of fatty acids that consume energy (Gauthier et al. 2008, Djouder et al. 2010) and in fine AMPK activation restrains hydrolysis of triglycerides (lipolysis). Acute treatment $(1 \mathrm{~h})$ with AICAR has been shown to decrease both NEFA and glycerol release in rat adipocytes (Gaidhu et al. 2009). In this study, AICAR decreased both NEFA and glycerol release in agreement with the results reported by Gaidhu et al. (2009). Apelin incubated during the same period did not acutely inhibit lipolysis in basal conditions or during isoprenaline-stimulated lipolysis. This could be due to the less sustained effect of apelin on AMPK phosphorylation. These results are thus different from those obtained with biguanides and thiazolidinediones that activate AMPK and inhibit stimulated lipolysis in human adipocytes (Bourron et al. 2010). Although apelin shares with those antidiabetic drugs, a decrease in glycemia, and activation of AMPK, apelin might not act on acute lipolysis.

Among the other metabolic functions of AT involving AMPK, we focused on glucose uptake. In this study, 

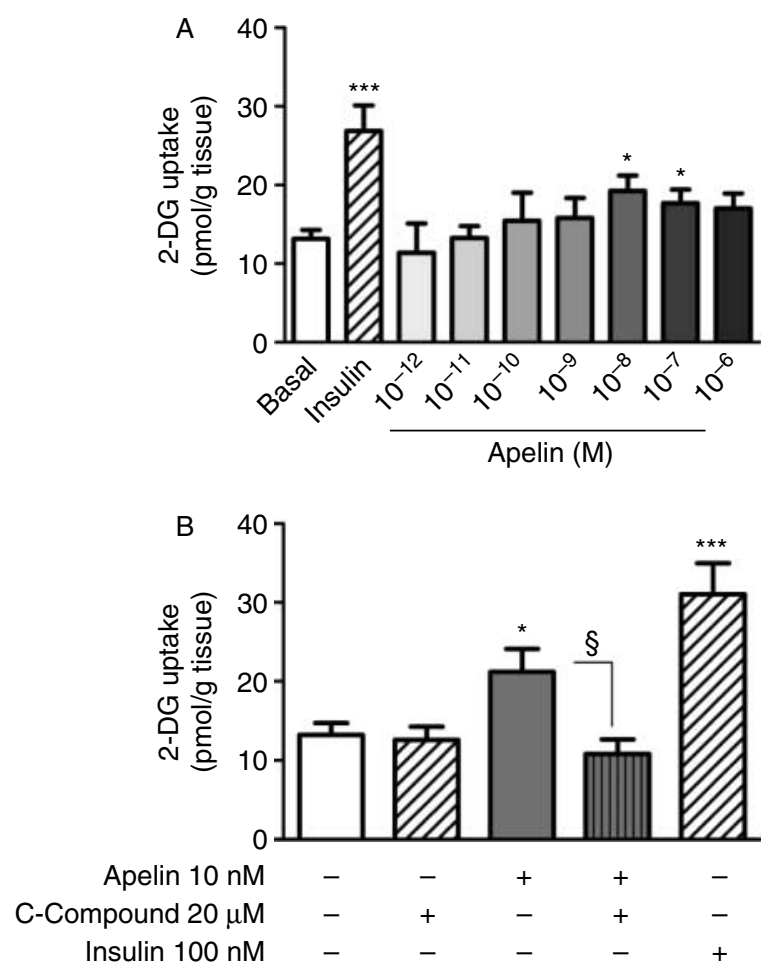

Figure 4 Apelin stimulates glucose uptake through AMPK activation. (A) AT explants were stimulated either with $100 \mathrm{nM}$ insulin or with the indicated concentrations of apelin as indicated in the section 'Materials and methods'. Results are the mean \pm S.E.M. of 7-12 independent experiments. ${ }^{\star} P<0.05$, ${ }^{\star * \star} P<0.001$ versus basal lipolysis (Basal). (B) Effect of $20 \mu \mathrm{M} C$ compound on basal and apelin-stimulated glucose uptake in AT explants. Insulin was used as a positive control. Values are the mean \pm S.E.M., $n=7$. ${ }^{\star} P<0.05,{ }^{\star \star \star} P<0.001$ versus basal. ${ }^{\S} P<0.05$ for apelin $10 \mathrm{nM}$ versus apelin $10 \mathrm{nM}+\mathrm{C}$ compound.

apelin had a modest effect on glucose uptake in human AT explants and isolated adipocytes. Insulin, at physiological concentrations, stimulated glucose transport in human AT explants twofold above basal, which is in agreement with previous studies performed on human isolated adipocytes (Iglesias-Osma et al. 2005, Wanecq et al. 2009) or differentiated cultured adipocytes (Hauner et al. 1998). It should be noticed that conversion of glucose into fatty acids (de novo lipogenesis) especially in AT is much lower in humans compared to rodents (Zelewski \& Swierczyński 1990). We choose to work first on AT explants with the aim to reproduce the conditions used for glucose transport ex vivo in muscle (Dray et al. 2008). It has been shown that functional activities are maintained in human AT explants (Moustaïd et al. 1996, Viguerie et al. 2002). Moreover, the effects of apelin were similar in AT explants and isolated adipocytes.

Only a few studies have demonstrated the role of AMPK in glucose uptake in adipose cells, and the mechanisms leading to AMPK activation in adipocytes remain poorly understood. The use of AICAR, as a pharmacological tool to activate this kinase, has not given conclusive results regarding its physiological role (Salt et al. 2000, Sakoda et al. 2002). Indeed, overexpression of a dominant negative form of AMPK in cultured adipocytes was shown to abolish AMPK activation without affecting AICAR-induced glucose transport (Sakoda et al. 2002). However, adiponectin, an insulin-sensitizing adipokine, was shown to increase glucose uptake in primary rat adipocytes through AMPK activation and this effect was abrogated in the presence of AMPK inhibitors (Wu et al. 2003). Similar results were obtained in this study with apelin. The effect of C compound, in blocking apelin-stimulated glucose uptake as well as the phosphorylation of ACC, strongly suggests a role of AMPK and thus an insulinindependent pathway for the effects of apelin. Yet, it is not known whether glucose uptake by adiponectin or apelin is dependent on glucose transporter-4 (GLUT4) translocation. GLUT4 is essential for insulin-stimulated glucose uptake in skeletal muscle and AT. Moreover, GLUT4 mRNA levels in human AT are detected mostly in mature adipocytes compared to the stroma vascular fraction or nonadipocyte cells (Vitkova et al. 2007). Consequently, the GLUT4-dependent effects are mainly due to adipocyte response. Activation of AMPK in different cell types could lead to translocation of GLUT4 transporters (Mu et al. 2001, Li et al. 2004), but not in all the reports (Lemieux et al. 2003, Breen et al. 2008). Moreover, studies performed in cultured 3T3-L1 preadipocytes or in C2C12 myoblasts demonstrated that AMPK is also implicated in GLUT1-mediated glucose uptake (Abbud et al. 2000). Hence, apelin could activate AMPK and glucose uptake through different GLUTs depending on the cell type (preadipocytes or adipocytes) involved.

In conclusion, these results show that apelin stimulates glucose uptake in human AT but to a less extent than insulin. Given that apelin is produced and secreted by AT, a local action of apelin could affect differently AT metabolic functions compared to insulin action. It will be of interest to depict these effects in obese subjects. Moreover, we also described AMPK activation by apelin in AT. Since the activation of AMPK is viewed as a therapeutic approach in obesity-associated disorders (type 2 diabetes) and since only few compounds have been described to activate AMPK in this tissue, the apelin/APJ system could be a promising target with potential beneficial effects in humans.

\section{Declaration of interest}

The authors declare that there is no conflict of interest that could be perceived as prejudicing the impartiality of the research reported. 


\section{Funding}

This work was supported by the INSERM and Paul Sabatier University.

\section{References}

Abbud W, Habinowski S, Zhang JZ, Kendrew J, Elkairi FS, Kemp BE, Witters LA \& Ismail-Beigi F 2000 Stimulation of AMP-activated protein kinase (AMPK) is associated with enhancement of Glut1mediated glucose transport. Archives of Biochemistry and Biophysics 380 347-352. (doi:10.1006/abbi.2000.1935)

Bai B, Tang J, Liu H, Chen J, Li Y \& Song W 2008 Apelin-13 induces ERK1/2 but not p38 MAPK activation through coupling of the human apelin receptor to the Gi2 pathway. Acta Biochimica et Biophysica Sinica 40 311-318. (doi:10.1111/j.1745-7270.2008. 00403.x)

Boucher J, Masri B, Daviaud D, Gesta S, Guigne C, Mazzucotelli A, Castan-Laurell I, Tack I, Knibiehler B, Carpene C et al. 2005 Apelin, a newly identified adipokine up-regulated by insulin and obesity. Endocrinology 146 1764-1771. (doi:10.1210/en.2004-1427)

Bourron O, Daval M, Hainault I, Hajduch E, Servant JM, Gautier JF, Ferré P \& Foufelle F 2010 Biguanides and thiazolidinediones inhibit stimulated lipolysis in human adipocytes through activation of AMP-activated protein kinase. Diabetologia 53 768-778. (doi:10. 1007/s00125-009-1639-6)

Breen DM, Sanli T, Giacca A \& Tsiani E 2008 Stimulation of muscle cell glucose uptake by resveratrol through sirtuins and AMPK. Biochemical and Biophysical Research Communications 374 117-122. (doi:10.1016/j.bbrc.2008.06.104)

Carpéné C, Dray C, Attané C, Valet P, Portillo MP, Churruca I, Milagro FI \& Castan-Laurell I 2007 Expanding role for the apelin/APJ system in physiopathology. Journal of Physiology and Biochemistry 63 358-373. (doi:10.1007/BF03165767)

Castan-Laurell I, Vitkova M, Daviaud D, Dray D, Kovacikova M, Kovacova Z, Hejnova J, Stich V \& Valet P 2008 Effect of hypocaloricinduced weight loss in obese women on plasma apelin and adipose tissue expression of apelin and AP. European Journal of Endocrinology 158 905-910. (doi:10.1530/EJE-08-0039)

Daval M, Foufelle F \& Ferré P 2006 Functions of AMP-activated protein kinase in adipose tissue. Journal of Physiology 574 55-62. (doi:10. 1113/jphysiol.2006.111484)

Djouder N, Tuerk RD, Suter M, Salvioni P, Thali RF, Scholz R, Vaahtomeri K, Auchli Y, Rechsteiner H, Brunisholz RA et al. 2010 PKA phosphorylates and inactivates AMPK $\alpha$ to promote efficient lipolysis. EMBO Journal 29 469-481. (doi:10.1038/emboj.2009.339)

Dray C, Knauf C, Daviaud D, Waget A, Boucher J, Buléon M, Cani PD, Attané C, Guigné C, Carpéné C et al. 2008 Apelin stimulates glucose utilization in normal and obese insulin-resistant mice. Cell Metabolism 8 437-445. (doi:10.1016/j.cmet.2008.10.003)

Dray C, Debard C, Jager J, Disse E, Daviaud D, Martin P, Attané C, Wanecq E, Guigné C, Bost F et al. 2010 Apelin and APJ regulation in adipose tissue and skeletal muscle of type 2 diabetic mice and humans. American Journal of Physiology. Endocrinology and Metabolism 298 E1161-E1169. (doi:10.1152/ajpendo.00598.2009)

Gaidhu MP, Fediuc S, Anthony NM, So M, Mirpourian M, Perry RL \& Ceddia RB 2009 Prolonged AICAR-induced AMP-kinase activation promotes energy dissipation in white adipocytes: novel mechanisms integrating HSL and ATGL. Journal of Lipid Research 50 704-715. (doi:10.1194/jlr.M800480-JLR200)

Gauthier MS, Miyoshi H, Souza SC, Cacicedo JM, Saha AK, Greenberg AS \& Ruderman NB 2008 AMP-activated protein kinase is activated as a consequence of lipolysis in the adipocyte: potential mechanism and physiological relevance. Journal of Biological Chemistry 283 16514-16524. (doi:10.1074/jbc.M708177200)

Hauner H, Röhrig K, Spelleken M, Liu LS \& Eckel J 1998 Development of insulin-responsive glucose uptake and GLUT4 expression in differentiating human adipocyte precursor cells. International Journal of Obesity and Related Metabolic Disorders 22 448-453. (doi:10.1038/sj.ijo.0800606)

Heinonen MV, Purhonen AK, Miettinen P, Paakkonen M, Pirinen E, Alhava E, Akerman K \& Herzig KH 2005 Apelin, orexin-A and leptin plasma levels in morbid obesity and effect of gastric banding. Regulatory Peptides 130 7-13. (doi:10.1016/j.regpep.2005.05.003)

Heinonen MV, Laaksonen DE, Karhu T, Karhunen L, Laitinen T, Kainulainen S, Rissanen A, Niskanen L \& Herzig KH 2009 Effect of diet-induced weight loss on plasma apelin and cytokine levels in individuals with the metabolic syndrome. Nutrition, Metabolism, and Cardiovascular Diseases 19 626-633. (doi:10.1016/j.numecd. 2008.12.008)

Higuchi K, Masaki T, Gotoh K, Chiba S, Katsuragi I, Tanaka K, Kakuma T \& Yoshimatsu H 2007 Apelin, an APJ receptor ligand, regulates body adiposity and favors the messenger ribonucleic acid expression of uncoupling proteins in mice. Endocrinology 148 2690-2697. (doi:10.1210/en.2006-1270)

Hutchinson DS, Chernogubova E, Dallner OS, Cannon B \& Bengtsson T $2005 \beta$-Adrenoceptors, but not $\alpha$-adrenoceptors, stimulate AMP-activated protein kinase in brown adipocytes independently of uncoupling protein-1. Diabetologia 48 2386-2395. (doi:10.1007/s00125-005-1936-7)

Iglesias-Osma MC, Bour S, Garcia-Barrado MJ, Visentin V, Pastor MF, Testar X, Marti L, Enrique-Tarancon G, Valet P, Moratinos J et al. 2005 Methylamine but not mafenide mimics insulin-like activity of the semicarbazide-sensitive amine oxidase-substrate benzylamine on glucose tolerance and on human adipocyte metabolism. Pharmacology Research 52 475-484. (doi:10.1016/j.phrs.2005.07.008)

Kadoglou NP, Tsanikidis H, Kapelouzou A, Vrabas I, Vitta I, Karayannacos PE, Liapis CD \& Sailer N 2010 Effects of rosiglitazone and metformin treatment on apelin, visfatin, and ghrelin levels in patients with type 2 diabetes mellitus. Metabolism 59 373-379. (doi:10.1016/j.metabol.2009.08.005)

Kleinz MJ \& Davenport AP 2005 Emerging roles of apelin in biology and medicine. Pharmacology and Therapeutics 107 198-211. (doi:10. 1016/j.pharmthera.2005.04.001)

Lafontan M 2008 Advances in adipose tissue metabolism. International Journal of Obesity 32 (Supplement 7) S39-S51. (doi:10.1038/ijo. 2008.237)

Lemieux K, Konrad D, Klip A \& Marette A 2003 The AMP-activated protein kinase activator AICAR does not induce GLUT4 translocation to transverse tubules but stimulates glucose uptake and p38 mitogen-activated protein kinases $\alpha$ and $\beta$ in skeletal muscle. FASEB Journal 17 1658-1665. (doi:10.1096/fj.02-1125com)

Li J, Hu X, Selvakumar P, Russell RR, Cushman SW, Holman GD \& Young LH 2004 Role of the nitric oxide pathway in AMPK-mediated glucose uptake and GLUT4 translocation in heart muscle. American Journal of Physiology. Endocrinology and Metabolism 287 E834-E841. (doi:10.1152/ajpendo.00234.2004)

Li L, Yang G, Li Q, Tang Y, Yang M, Yang H \& Li K 2006 Changes and relations of circulating visfatin, apelin, and resistin levels in normal, impaired glucose tolerance, and type 2 diabetic subjects. Experimental and Clinical Endocrinology and Diabetes 114 544-548. (doi:10.1055/s-2006-948309)

Masri B, Lahlou H, Mazarguil H, Knibiehler B \& Audigier Y 2002 Apelin (65-77) activates extracellular signal-regulated kinases via a PTX-sensitive G protein. Biochemical and Biophysical Research Communications 290 539-545. (doi:10.1006/bbrc.2001.6230)

Moustaïd N, Jones BH \& Taylor JW 1996 Insulin increases lipogenic enzyme activity in human adipocytes in primary culture. Journal of Nutrition $126865-870$.

Mu J, Brozinick JT, Valladares O, Bucan M \& Birnbaum MJ 2001 A role for AMP-activated protein kinase in contraction- and hypoxiaregulated glucose transport in skeletal muscle. Molecular Cell 7 1085-1094. (doi:10.1016/S1097-2765(01)00251-9)

Omar B, Zmuda-Trzebiatowska E, Manganiello V, Göransson O \& Degerman E 2009 Regulation of AMP-activated protein kinase by 
cAMP in adipocytes: roles for phosphodiesterases, protein kinase B, protein kinase A, Epac and lipolysis. Cellular Signalling 21 760-766. (doi:10.1016/j.cellsig.2009.01.015)

Sakoda H, Ogihara T, Anai M, Fujishiro M, Ono H, Onishi Y, Katagiri H, Abe M, Fukushima Y, Shojima N et al. 2002 Activation of AMPK is essential for AICAR-induced glucose uptake by skeletal muscle but not adipocytes. American Journal of Physiology. Endocrinology and Metabolism 282 E1239-E1244. (doi:10.1152/ajpendo.00455.2001)

Salt IP, Connell JM \& Gould GW 2000 5-Aminoimidazole-4-carboxamide ribonucleoside (AICAR) inhibits insulin-stimulated glucose transport in 3T3-L1 adipocytes. Diabetes 49 1649-1656. (doi:10. 2337/diabetes.49.10.1649)

Soriguer F, Garrido-Sanchez L, Garcia-Serrano S, Garcia-Almeida JM, Garcia-Arnes J, Tinahones FJ \& Garcia-Fuentes E 2009 Apelin levels are increased in morbidly obese subjects with type 2 diabetes mellitus. Obesity Surgery 19 1574-1580. (doi:10.1007/s11695-0099955-y)

Tatemoto K, Hosoya M, Habata Y, Fujii R, Kakegawa T, Zou MX, Kawamata Y, Fukusumi S, Hinuma S, Kitada C et al. 1998 Isolation and characterization of a novel endogenous peptide ligand for the human APJ receptor. Biochemical and Biophysical Research Communications 251 471-476. (doi:10.1006/bbrc.1998.9489)

Viguerie N, Millet L, Avizou S, Vidal H, Larrouy D \& Langin D 2002 Regulation of human adipocyte gene expression by thyroid hormone. Journal of Clinical Endocrinology and Metabolism 87 630-634. (doi:10.1210/jc.87.2.630)

Vitkova M, Klimcakova E, Kovacikova M, Valle C, Moro C, Polak J, Hanacek J, Capel F, Viguerie N, Richterova B et al. 2007 Plasma levels and adipose tissue messenger ribonucleic acid expression of retinol-binding protein 4 are reduced during calorie restriction in obese subjects but are not related to diet-induced changes in insulin sensitivity. Journal of Clinical Endocrinology and Metabolism 92 2330-2335. (doi:10.1210/jc.2006-2668)

Wanecq E, Prévot D \& Carpéné C 2009 Lack of direct insulin-like action of visfatin/Nampt/PBEF1 in human adipocytes. Journal of Physiology and Biochemistry 65 351-360. (doi:10.1007/BF03185930)

Wu X, Motoshima H, Mahadev K, Stalker TJ, Scalia R \& Goldstein BJ 2003 Involvement of AMP-activated protein kinase in glucose uptake stimulated by the globular domain of adiponectin in primary rat adipocytes. Diabetes 52 1355-1363. (doi:10.2337/ diabetes.52.6.1355)

Yin W, Mu J \& Birnbaum MJ 2003 Role of AMP-activated protein kinase in cyclic AMP-dependent lipolysis in 3T3-L1 adipocytes. Journal of Biological Chemistry 278 43074-43080. (doi:10.1074/jbc. M308484200)

Yue P, Jin H, Aillaud-Manzanera M, Deng AC, Azuma J, Asagami T, Kundu RK, Reaven GM, Quertermous T \& Tsao PS 2009 Apelin is necessary for the maintenance of insulin sensitivity. American Journal of Physiology. Endocrinology and Metabolism 298 E59-E67. (doi:10.1152/ajpendo.00385.2009)

Zelewski M \& Swierczyński J 1990 Comparative studies on lipogenic enzyme activities in the liver of human and some animal species. Comparative Biochemistry and Physiology 95 469-472. (doi:10.1016/ 0305-0491(90)90004-D)

Received in final form 5 October 2010 Accepted 9 November 2010

Made available online as an Accepted Preprint 9 November 2010 